Editorial

\title{
Introduction to the Special Issue: Policy for Low-Carbon Transformations
}

\author{
Marc Dijk ${ }^{1, *}$ and Paula Kivimaa ${ }^{2,3, *}$ \\ 1 International Centre of Integrated Assessment and Sustainable Development (ICIS), Maastricht University, \\ 6200 MD Maastricht, The Netherlands \\ 2 SPRU and Centre on Innovation and Energy Demand, University of Sussex, Falmer, \\ East Sussex BN1 9RH, UK \\ 3 Finnish Environment Institute SYKE, 00790 Helsinki, Finland \\ * Correspondence: m.dijk@maastrichtuniversity.nl (M.D.); Paula.Kivimaa@ymparisto.fi (P.K.)
}

Received: 29 May 2020; Accepted: 1 September 2020; Published: 6 September 2020

check for updates

\section{Policy Mixes, Policy Innovations and Policy Coherence Influencing Low-Carbon Energy Transformations}

Gradual changes in energy and mobility systems in recent decades have triggered new and significant policy challenges. Both the energy and mobility fields have increasingly embraced sustainability goals and are influenced by rapid developments in ICT and digitalization. Energy and mobility, the foci of this Special Issue, have always been connected at the supply side (through fuel use in particular). However, they are also increasingly interconnected through the electrification of mobility, the decentralization of energy systems (where, e.g., electric vehicles can also be used as storage), and the development of smart energy and mobility systems.

These developments have created new needs and demands for public policy. Such demands include, for example, the achievement of more coherent policy frameworks across an increasing number of administrative domains and different levels of governance to maximise synergies and reduce contradictions between policies, phase-out and exnovation policies to speed up low-carbon transformation, as well as innovative and experimental policies to tackle the persistent problems caused by high-carbon societies. As novel integrated business models for the provision of mobility or energy services increasingly involve cross-sector innovation (coupling between, e.g., energy, transport, construction, finance, and information technology), the role of 'real-world' policy mixes becomes more significant than before. Such policy mixes cross administrative domains and levels, and need to be adjusted to support sustainability transitions through coherent and consistent policymaking. New insights into policy mixes are needed in real time as new systemic innovations and integrated services emerge. Recent research also highlights the importance of policy innovation and policy and governance experimentation to tackle the climate change challenge. Empirical accounts of such innovations and experimentations are needed to shed light into what they look like, what they have enabled, and how they might fit within existing policy mixes in support of sustainable low-carbon transitions.

This Special Issue emerged from an interest in policy mixes and policy innovations linked to energy and mobility transitions, and the coherence of policy goals, instruments and processes. The policy mixes perspective on sustainability transitions addresses how policy goals, strategies, instruments - and sometimes also policy processes-are in interplay with each other and have a combined effect, supporting or hindering low-carbon transitions. This mutual dependency of policies means that policy analysis should increasingly focus on the combined effects of policy mixes when designing, evaluating and reframing policies-not on the effect of single instruments, as many earlier policy studies do. This topic has gained in interest in the last five years in the context of energy and 
sustainability transitions, with two Special Issues published in 2017 (in Energy Research and Social Science) and 2019 (in Research Policy).

Policy innovation implies novel approaches and designs in either policy processes or instruments. While, sometimes, policy innovation has been used to refer to policy change more generally, research has since become more specific. For instance, novel goals, new types of leverage mechanisms, new implementing organizations, or new target groups can function as a characteristic of policy innovation-which can occur as new to the world, new to a country or new to a sector. Some policy changes framed as innovations can be merely symbolic, or on the other hand, genuine policy innovations may go undetected to the outside when radical modifications have been made to policy instruments or processes, without changing the names given to policies. Policy experimentation may take place before policy innovations emerge, while policy innovations may occur without specific experimentation beforehand and policy experimentation may also lead to other types of governance changes, such as changes in policy evaluation or institutional change. Whether these experimental approaches end up as policy innovation depends, among other things, on political leadership. It is also important to note that policy innovations may not always easily fit into the existing policy mixes, with implications on the coherence of policies.

A uniform definition of policy coherence does not exist in the academic literature, and it has been used in the context of differing policy domains, such as foreign and security policy, development policy and climate policy. This may not be surprising (and not necessarily be problematic) regarding the complex context of policy. After all, coherence plays a role in many dimensions. In the context of environmental policy studies, coherence is frequently understood a systematic reduction of conflicts and promotion of synergies between and within different policy domains (their goals, instruments and processes). The OECD has recommended an increase in "the coherence of the instrument mix" for environmental policy for more than a decade. The great complexity of low-carbon transformations is that effective policy requires coherence between all these dimensions: policy domains, goals and instruments, but also governance layers, low-carbon and high-carbon practices, etc. Yet, at the same time, significant policy changes are also needed, which may reduce the coherence between policy domains over time, at least temporarily. This is one of the big challenges facing public policy makers in the coming years. Thus, there is a need for more ex-post policy analyses and evaluations to increase our knowledge on how policy affects transitions, and new frameworks for ex-ante analysis. From an evidence-based policy-making perspective, ex-ante evaluations need to use knowledge gained through ex-post evaluations, a crucial link in the policy cycle.

\section{Contributions of the Special Issue}

The six articles comprising this Special Issue in Energies contribute to the search for more information on the policy challenge to low-carbon transformation, each in their own way. They seek to explore the current state and effectiveness of policies in relation to low-carbon transitions in energy and mobility and discuss and draw policy recommendations. The contributions reflect a variety of geographies (two continents, seven countries, two cities), and policy domains, as we discuss below. They include three ex-post and three ex-ante studies.

Schippl and Arnold (2020) [1] study the role of policy in low-carbon urban mobility futures in Stuttgart. The article addresses coherence between various modes of urban mobility (more and less sustainable ones), and their co-evolution with digitalization. In their discussion of the role of urban mobility policies, the authors especially involve environmental goals, less economic and social (equity) ones. Based on 10 semi-structured interviews with providers of innovative mobility services, the authors find broad agreement that digitalization alone is not enough to achieve a full-scale transition towards multimodal urban mobility. Policy measures that restrict car-based mobility would also be needed. However, the study also reveals doubt that the essential policy mixes will find the necessary political and societal acceptance. 
Kaszyński and Kamiński (2020) [2] explore future trends of the power sector in Poland, including coherence between a range of fuel and energy sources (renewable and non-renewables). Based on model analysis, the article determines how environmental policies affect the future demand for various energy sources (ranging from renewables to hard coal and brown coal) in the Polish power sector by 2050. The analysis includes interferences of national and European policies and directives and refers to environmental and economic goals. Kaszyński and Kamiński show the strong interference of Polish and EU regulation in trajectories of national power supply. EU regulation is critical for reducing the role of coal. The price of $\mathrm{CO}_{2}$ emission allowances and stricter emission standards stemming from the Industrial Emissions Directive and the Best Available Techniques (BAT) had the largest influence on the reduction in hard coal demand. In the case of brown coal, no new power-generating units would be deployed; hence, brown coal consumption would drop practically to zero in 2050 under all the scenarios considered.

Berg, Lukkarinen and Ollikka (2020) [3] address policy trajectories promoting particular renewable energy technologies in Denmark, Germany and Finland. Their scope includes one renewable energy type in each country addressed from the perspective of multi-policy goals, multiple types of instruments, and multiple governance layers. The effect of these policies is connected to broader societal processes. The study concentrates particularly on a phenomenon that is common for the three countries-the long-term commitment to these policies. The article finds that, while all the case countries have generated robust renewable energy policy goals, Finland has failed to foster resilience (i.e., the ability of policy to cope with both external shocks and internal perturbations) simultaneously. They conclude that analyzing the 'stickiness' (i.e., the long-term commitment) of policy elements can be fruitful in understanding and designing transformative policies.

Mao, Ma, Wang, and Bian (2019) [4] examine a case of Qihe County in Shandong, China, focusing on policy instruments adopted for low-carbon city development and the effectiveness of these instruments. The article analyzes multi-policy goals, two policy domains (energy and mobility), various types of instruments (compulsory, mixed and voluntary), and layers (urban and national level). All the policies adopted by the piloted city from 2008 and 2014 were included in the analysis, grouped into compulsory, voluntary and mixed instruments. The paper highlights the strong influence of national instruments on urban development in China. The results show that the key goal of China's low-carbon city construction is to develop low-carbon technology and low-carbon energy. Compulsory policy instruments are the most used and most effective, while voluntary policy instruments are rarely used. The article finds that the county's low-carbon city construction policy completion degree is high, with relatively stable effects brought by compulsory policy instruments. The results also reveal that, in the field of low-carbon city construction, high accomplishment and high stability of various policy instruments can seldom be simultaneously achieved.

Wang and $\mathrm{Li}$ (2019) [5] offer a model-based (policy) scenario analysis for electric power supply in China (2020-2035), addressing four potential pathways of policies for long-term energy transformation. Within the scope are potential effects of various types of instruments, all at the national level. The article considers economic and environmental criteria, as well as various types of energy sources (renewables and fossil fuels). They assess the impact of four policy strategies on the share of various types of energy sources (renewables and fossil fuels), electricity prices, capacity factors, $\mathrm{CO}_{2}$ emissions, etc. The study concludes that the focus of China's future power industry planning should be to accelerate the pace of power marketization and to formulate a sound carbon policy to reduce coal consumption, accelerate energy transformation, and promote clean energy consumption.

Dijk, Iversen, Klitkou, Kemp, Bolwig, Borup, and Møllgaard (2020) [6] evaluate how policy shaped the emergence of electric mobility in three countries-Norway, the Netherlands and Denmark - between 2010 and 2015. Their scope includes different forms of car mobility and energy; various types of instruments, and multiple governance levels. Based on analysis of synergetic, contradictory and pre-conditional effects between five policy sub-fields, the article finds that an effective policy mix includes: fiscal incentives that mirror the actual carbon footprint of the respective vehicles; non-fiscal 
demand-side incentives; centrally financed and/or coordinated charging infrastructure; clarity regarding the choice of recharge technology that will be supported. The findings can be helpful for designing policy mixes in the transition to electric mobility.

\section{Insights in the Multifarious Dimensions of Policy Coherence}

The articles in this Special Issue give insight into the various dimensions of policy coherence, while less is revealed about policy innovation. Table 1 maps the scope of the articles in four of these dimensions of policy coherence that are significant in low-carbon transformations. Throughout the contributions, policy coherence as a concept is tied to the nature and effectiveness of policy mixes, although the latter concept is not explicitly addressed in all the articles. Here, we focus on selected insights on policy coherence and connect these to some of the findings from the Special Issue articles.

Table 1. Mapping the six articles regarding scope in four key dimensions of policy coherence in low carbon transformation.

\begin{tabular}{|c|c|c|c|c|}
\hline \multirow[b]{2}{*}{ Dimension } & \multicolumn{4}{|c|}{ Scope } \\
\hline & & & & \\
\hline \multirow[t]{4}{*}{$\begin{array}{c}\text { Policy goals \& } \\
\text { criteria }\end{array}$} & $\begin{array}{l}\text { Environmental } \\
\text { quality }\end{array}$ & Economic impact & Social equity & \\
\hline & \multicolumn{3}{|c|}{$\begin{array}{l}\text { Berg, Lukkarinen and Ollikka } \\
\text { Mao et al. }\end{array}$} & \\
\hline & \multicolumn{2}{|c|}{$\begin{array}{l}\text { Kaszyński and Kamiński } \\
\text { Wang and Li } \\
\text { Dijk et al. }\end{array}$} & & \\
\hline & Schippl and Arnold & & & \\
\hline \multirow[t]{3}{*}{ Policy domains } & Mobility \& energy & $\begin{array}{c}\text { Either mobility or } \\
\text { energy }\end{array}$ & $\begin{array}{l}\text { One mobility mode } \\
\text { or energy practice }\end{array}$ & $\begin{array}{l}\text { Mobility \& energy } \\
\text { plus related fields }\end{array}$ \\
\hline & & $\begin{array}{l}\text { Schippl and Arnold } \\
\text { Kaszyński and } \\
\text { Kamiński } \\
\text { Wang and Li }\end{array}$ & Berg et al. & \\
\hline & $\begin{array}{l}\text { Dijk et al. } \\
\text { Mao et al. }\end{array}$ & & & \\
\hline \multirow[t]{6}{*}{ Governance levels } & Local/regional & National & Supranational & \\
\hline & Schippl and Arnold & & & \\
\hline & & Wang and $\mathrm{Li}$ & & \\
\hline & & \multicolumn{2}{|c|}{ Kaszyński and Kamiński } & \\
\hline & \multicolumn{2}{|c|}{ Mao et al. } & & \\
\hline & & $\begin{array}{c}\text { Dijk et al. } \\
\text {, Lukkarinen and Oll }\end{array}$ & & \\
\hline \multirow[t]{4}{*}{$\begin{array}{l}\text { Types of } \\
\text { instruments }\end{array}$} & Regulation & Taxes \& subsidies & $\begin{array}{l}\text { Public procurement } \\
\& \text { soft instruments }\end{array}$ & $\begin{array}{l}\text { Multi-actor } \\
\text { platforms or } \\
\text { experiments }\end{array}$ \\
\hline & \multicolumn{4}{|c|}{$\begin{array}{c}\text { Schippl and Arnold } \\
\text { Dijk et al. } \\
\text { Berg, Lukkarinen and Ollikka }\end{array}$} \\
\hline & \multicolumn{3}{|c|}{ Mao et al. } & \\
\hline & $\begin{array}{r}\text { Kaszyński a } \\
\text { Wang }\end{array}$ & $\begin{array}{l}\text { Id Kamiński } \\
\text { and Li }\end{array}$ & & \\
\hline
\end{tabular}

The first dimension is the coherence of policy goals. Policy frameworks and mixes for low-carbon transformation should not and cannot optimize towards one policy goal (hence, economic, environmental or social), but achieve multiple goals at the same time. This is increasingly demonstrated by the new attention given in environmental sustainability debates to social justice questions. As Table 1 
shows, in this Special Issue, that Berg et al. (2020) [3] have a particularly broader scope and their approach to analyze long-term policy trajectories in relation to other societal goals and developments is promising in this regard. Many of the other contributions are more limited in terms of the scope of policy goals. A well-known tool such as multi-criteria analysis can be helpful to broaden the scope and to assess the coherence of multiple policy goals.

Second, low-carbon transformation crosses various policy domains, and the coherence between policies in the various fields, i.e., horizontal policy coherence, is significant in the analysis of low-carbon transformation. Without dismissing the important role of policy studies focused on one particular mobility mode (e.g., either cycling, public transport or car mobility) or one particular energy practice (such as heating our homes), policy analysis for low-carbon transformation should address the coherence of policies across different domains (such as energy and mobility policies) or sub-domains (such as different mobility modes or energy practices). Indeed, beyond these two fields, understanding the interference with other fields like spatial planning and food is required, which signals the need for more 'nexus' studies that have emerged in the last decade. In this Special Issue, the article by Schippl and Arnold examines coherence between car constraining policies, and policies promoting car alternatives, at an urban level. Their analysis shows that understanding the ideal policy mix for low-carbon transition does not mean that there is social support for it. The article by Dijk et al. is an example of an analysis including the interference of mobility and energy policies. In addition to synergies in terms of vehicle technology and associated energy (generation) efficiency, the study shows the significance of policy coherence for public support of low-carbon mobility modes with constraining policies for carbon-intensive modes.

Third, low-carbon transformation policies studies should consider the interference of local, national and supranational policies. For instance, in most Western countries, urban mobility is to a large extent shaped by decentralized competences and policy instruments of cities. At the same time, there are national programmes, laws, etc., enabling as well as limiting what cities (can) do. Finally, in EU countries, cities are shaped by EU instruments such as (i) regulation and planning (e.g., rules on public procurement, urban mobility and air quality plans); (ii) networks and partnerships (e.g., Eurocities, EU Urban Agenda); (iii) innovation funding programs (e.g., EU Cohesion policy, Horizon 2020). As Table 1 shows, most articles in this special include at least two layers of governance. Only for some cases (such as the electric power supply in the Chinese governance context, the article by Wang and $\mathrm{Li} \mathrm{(2019)} \mathrm{[5]),} \mathrm{a} \mathrm{single-layer} \mathrm{approach} \mathrm{is} \mathrm{effective,} \mathrm{but} \mathrm{in} \mathrm{general,} \mathrm{it} \mathrm{is} \mathrm{recommendable} \mathrm{that} \mathrm{the}$ influence of multiple layers is at least explored. Kaszyński and Kamiński (2020) [2] show the strong interference of Polish and EU regulation in trajectories of national power supply. EU regulation turns out to be critical for reducing the role of coal. Mao et al. (2019) [4] highlight the strong influence of national instruments on urban development in China. Lastly, one of the key reasons for Norway's global lead in E-mobility market share was the alignment of national policies for E-mobility (especially financial purchase support) with particular local user benefits (such as parking and use of the car-pool lane) (Dijk et al. 2020) [6].

Fourth, the coherence between various types of policy instruments (such as regulation, taxes, public procurement, soft measures, multi-actor platforms and experiments) is significant for a low-carbon transformation policy. As Table 1 shows, all articles in the Special Issues address more than one type of instrument in their analysis, although the concept of policy interaction is not explicitly addressed in all of them. Dijk et al. (2020)'s [6] analysis of synergetic, contradictory and pre-conditional effects between five policy sub-fields, discusses the role of stakeholder platforms for e-mobility as a form of governance in Norway and the Netherlands. It was a form of strategic collaboration and coordination between the private sector and the government that supported learning about the most significant bottlenecks and identifying and discussing useful interventions. Regarding the recent surge in policy attention for 'experimentation' in the context of climate and other sustainability challenges, an important point for future research is the alignment of these (innovation or transition) experiments or Living Labs with established instruments. Experiments easily become a pet topic of a limited number 
of enthusiasts, disconnected from mainstream practices and actors. However, without the proper alignment (or 'embedding') with the latter, experiments tend to stay small and have little impact.

As the future unfolds, and as climate change continues to show effect, the policy discussions in this Special Issue will only increase in urgency and importance. Since low-carbon transformation is a process taking decades, policies will (need to) evolve and adapt over time. In every phase, policy coherence is significant and therefore likely will remain a topic of much interest and attention.

Author Contributions: Conceptualization, M.D. and P.K.; Writing-Original Draft Preparation, M.D. and P.K.; Writing-Review \& Editing, M.D. and P.K.; Visualization, M.D. All authors have read and agreed to the published version of the manuscript.

Funding: This research received no external funding.

Conflicts of Interest: The authors declare no conflict of interest.

\section{References}

1. Schippl, J.; Arnold, A. Stakeholders' Views on Multimodal Urban Mobility Futures: A Matter of Policy Interventions or Just the Logical Result of Digitalization? Energies 2020, 13, 1788. [CrossRef]

2. Kaszyński, P.; Kamiński, J. Coal Demand and Environmental Regulations: A Case Study of the Polish Power Sector. Energies 2020, 13, 1521. [CrossRef]

3. Berg, A.; Lukkarinen, J.; Ollikka, K. 'Sticky' Policies-Three Country Cases on Long-Term Commitment and Rooting of RE Policy Goals. Energies 2020, 13, 1351. [CrossRef]

4. Mao, Q.; Ma, B.; Wang, H.; Bian, Q. Investigating Policy Instrument Adoption in Low-Carbon City Development: A Case Study from China. Energies 2019, 12, 3475. [CrossRef]

5. Wang, P.; Li, M. Scenario Analysis in the Electric Power Industry under the Implementation of the Electricity Market Reform and a Carbon Policy in China. Energies 2019, 12, 2152. [CrossRef]

6. Dijk, M.; Iversen, E.; Klitkou, A.; Kemp, R.; Bolwig, S.; Borup, M.; Møllgaard, P. Forks in the Road to E-Mobility: An Evaluation of Instrument Interaction in National Policy Mixes in Northwest Europe. Energies 2020, 13, 475. [CrossRef] 